\title{
Coulometric response characteristics of solid contact ion-selective electrodes for divalent cations
}

\author{
Tingting Han ${ }^{1} \cdot$ Zekra Mousavi $^{1}$ (D) $\cdot$ Ulriika Mattinen $^{1}$ (D) $\cdot$ Johan Bobacka $^{1}$ (D)
}

Received: 23 April 2020 / Revised: 6 June 2020 / Accepted: 7 June 2020 / Published online: 15 June 2020

(C) The Author(s) 2020

\begin{abstract}
The chronoamperometric and coulometric response of solid contact ion-selective electrodes (SCISEs) for the detection of divalent cations was investigated in order to provide a more complete description of the mechanism of the recently introduced coulometric transduction method for SCISEs. The coulometric transduction method has earlier been employed only for SCISEs that were selective to monovalent ions. The SCISEs utilized poly(3,4-ethylenedioxythiophene) (PEDOT) doped with poly(styrene sulfonate) $\left(\mathrm{PSS}^{-}\right.$) as the solid contact (ion-to-electron transducer). PEDOT(PSS) was electrodeposited on glassy carbon and covered with plasticized PVC-based ion-selective membranes (ISMs) that were selective towards divalent cations $\left(\mathrm{Ca}^{2+}, \mathrm{Pb}^{2+}\right)$. In contrast to earlier studies, the results obtained in this work show that the coulometric response for the $\mathrm{Pb}^{2+}-\mathrm{SCISE}$ was limited mainly by ion transport in the PEDOT(PSS) layer, which was not the case for the $\mathrm{Ca}^{2+}$-SCISE, nor was it observed earlier for the monovalent ions. The exceptional behavior of the $\mathrm{Pb}^{2+}$-SCISE was explored further by electrochemical impedance spectroscopy, and it was shown that the effective redox capacitance of PEDOT(PSS) was significantly higher for the $\mathrm{Pb}^{2+}$-SCISE than for the $\mathrm{Ca}^{2+}$-SCISE although the polymerization charge of PEDOT(PSS) was the same. The slow transport of $\mathrm{Pb}^{2+}$ in PEDOT(PSS) was tentatively related to complexation between $\mathrm{Pb}^{2+}$ and PEDOT(PSS).
\end{abstract}

Keywords Solid contact ISE $\cdot$ Divalent cations $\cdot$ Coulometric transduction $\cdot$ Charge transfer $\cdot$ Impedance

\section{Introduction}

Ion-selective electrodes (ISEs) are important analytical tools that are widely used in many fields related to our daily life, such as clinical diagnostics, environmental monitoring, agriculture, and food industry [1-5]. Thus, there is a great demand for durable, easy-to-use, and less-frequently calibrated ISEs. Over the years, the performance of ISEs has been significantly improved. The detection limit of polymeric membrane-based ISEs was lowered to ca. $10^{-11} \mathrm{M}$ by adjusting the internal filling solution in the traditional design [6]. The so-called solid contact ion-selective electrodes (SCISEs) were developed in order to overcome limitations of the internal filling solution, i.e., to obtain more durable sensors that are easy to manufacture, can be miniaturized, and

Wishing Professor Fritz Scholz a happy 65th birthday!

Johan Bobacka

johan.bobacka@abo.fi

1 Johan Gadolin Process Chemistry Centre, Laboratory of Molecular Science and Engineering, Åbo Akademi University, Biskopsgatan 8, FI-20500 Åbo, Finland require little maintenance. Among various solid contact materials in SCISEs, conducting polymers proved to be useful as their mixed ion-electron conductivity and high redox (pseudo) capacitance improved the potential stability of the SCISE $[5,7]$. The conducting polymer poly(3,4-ethylenedioxythiophene) (PEDOT) doped with polystyrene sulfonate ( $\mathrm{PSS}^{-}$) has been extensively used as solid contact in the fabrication of SCISEs for ions, such as $\mathrm{K}^{+}[8], \mathrm{Ca}^{2+}[9]$, and lead $\mathrm{Pb}^{2+}[9,10]$. The potential of the conducting polymer itself depends both on its redox state (doping level) and on the ion activity in the contacting solution $[11,12]$. Thus, it was shown that the standard potential of SCISEs with PEDOT as solid contact can be shifted by applying either a potential which deviates from the open circuit potential of the electrode or by applying current pulses [13]. These results showed that the redox state of PEDOT can be changed electrochemically even after PEDOT is coated by an ion-selective membrane. Also short circuiting of the SCISE with a conventional large-capacitance reference electrode showed to be a promising way of controlling the standard potential of SCISEs [14]. The reversible reduction/oxidation of the conducting polymer solid contact was also utilized to detect two different analytes with a single SCISE [15]. 
Traditionally, ISE measurements are carried out using the so-called zero-current potentiometric method, where the equilibrium potential of the ISE, measured vs a reference electrode, is dependent on the ion activity of the primary ion in the sample [5]. In recent years, non-zero current measurements of ISEs have attracted considerable attention [16]. Some of these alternative measurement modes are chronopotentiometry [17, 18], voltammetry [19-22], and constant potential coulometry [23]. Voltammetric methods were introduced to ISEs by employing thin-layer ion-selective membranes [19]. Amemiya et al. reported the analysis of nanomolar concentrations of perchlorate in drinking water using ion-transfer stripping voltammetry [20]. Bakker's group presented simultaneous detection of multiple ion activities using a thin-layer ionophore-based membrane and cyclic voltammetry [21, 22].

A new constant potential coulometric method was introduced by our group [23, 24]. In this method, the potential of the SCISE vs the reference electrode is kept constant, so that any potential change at the ion-selective membrane (ISM)sample interface, due to a change in ion activity in the solution, causes oxidation/reduction of the PEDOT solid contact. The analytical signal is thus a transient current that is measured and integrated to obtain the charge corresponding to the change in the logarithm of ion activity in solution [23, 24]. The method was investigated using PEDOT as solid contact in SCISEs for the detection of monovalent ions, such as $\mathrm{K}^{+}$ [24-26], $\mathrm{Cl}^{-}$[27] and $\mathrm{H}^{+}(\mathrm{pH})$ [26]. The unique feature of this coulometric method is that the analytical signal, i.e., charge (for a given change in ion activity) is proportional to the redox capacitance of the solid contact, meaning that the signal can be amplified by increasing the thickness (loading) of the solid contact layer [24]. This method has the potential to be used for detecting very small concentration changes, e.g., in clinical applications where the relevant concentration ranges of several ions are very narrow. For example, the concentration range of $\mathrm{K}^{+}$ion in blood serum is $3.5-5.1 \mathrm{mmol} \mathrm{dm}^{-3}$ [1]. An initial drawback of the coulometric method was a relatively long response time [23, 24]. However, by lowering the bulk resistance of the ion-selective membrane, either by increasing the geometrical surface area of the electrode [25] or by using spincoated thin-layer ISMs [26, 27], it was possible to significantly shorten the response time of the coulometric signal readout method. Based on a capacitance model used earlier for SCISEs [8], the theory of the coulometric readout was developed for $\mathrm{Cl}^{-}$-SCISEs [27]. Furthermore, coulometric SCISEs were evaluated for measurement of $\mathrm{pH}$ in seawater [26] and $\mathrm{K}^{+}$in serum $[26,28]$.

The measured coulometric signal for SCISEs is based on a current transient involving a change in the redox state (doping level) of the conducting polymer (PEDOT) requiring transport of charge-compensating ions through the ISM and PEDOT layers. This means that the coulometric response may be limited by ion transport through the bulk of the ISM or PEDOT, or by ion transfer at the PEDOT-ISM or ISM-solution interfaces. A theoretical capacitive model based on a series $R C$ circuit gave an excellent explanation of the coulometric response of a $\mathrm{Cl}^{-}$SCISE [27]. However, impedance measurements showed that the coulometric response for $\mathrm{K}^{+}$-SCISEs was limited by diffusion even for thin-layer ISMs [26]. Mikhelson et al. presented recently an extended theoretical model for the amperometric and coulometric response of $\mathrm{K}^{+}$-SCISEs by considering also concentration polarization in the ISM [28].

A further study of the coulometric response and the corresponding charge transfer processes of SCISEs is undertaken in this work to strengthen our understanding of the coulometric transduction mechanism. In this work, the transfer of divalent cations in SCISEs is studied using chronoamperometry, constant potential coulometry, and electrochemical impedance spectroscopy. The electrochemical characteristics of SCISEs with different thicknesses of PEDOT(PSS), as well different thicknesses of ISMs, were studied for lead-selective SCISEs $\left(\mathrm{Pb}^{2+}\right.$-SCISEs) and calcium-selective SCISEs ( $\mathrm{Ca}^{2+}{ }_{-}$SCISEs).

\section{Experimental}

\section{Materials}

Calcium ionophore IV, lead ionophore IV, valinomycin, potassium tetrakis[3,5-bis-(trifluoromethyl)-phenyl]borate (KTFPB), potassium tetrakis(4-chlorophenyl)borate (KTpClPB), tetradodecylammonium tetrakis(4chlorophenyl)borate (ETH-500), 2-nitrophenyl octyl ether (o-NPOE), bis(2-ethylhexyl)sebacate (DOS), poly(vinyl chloride) (PVC) of high molecular weight, and tetrahydrofuran (THF, $>99.5 \%$ ) were selectophore reagents purchased from Fluka. Poly(sodium 4-styrenesulfonate) (NaPSS, Mw 70,000), 3,4-ethylenedioxythiophene (EDOT, 97\%), calcium chloride, lead nitrate, potassium chloride, and sodium chloride were purchased from Sigma-Aldrich. Deionized water (ELGA Purelab Ultra; resistivity $18.2 \mathrm{M} \Omega \mathrm{cm}$ ) was used for preparing the aqueous solutions.

\section{Electrode preparation}

Glassy carbon (GC) disk electrodes (3-mm diameter) used in this work were manufactured in-house by inserting a 3-mm diameter GC rod (SIGRADUR G, Germany) into a hard PVC cylinder using mechanical pressure. The GC disk electrodes were then extensively polished to smooth, mirror-like finish using the following steps: polishing with abrasive papers of different coarseness, then diamond pastes with particle diameters of $15 \mu \mathrm{m}, 9 \mu \mathrm{m}, 3 \mu \mathrm{m}$, and $1 \mu \mathrm{m}$, respectively, and finally with $0.3-\mu \mathrm{m}$ aluminum dioxide paste. Immediately after that, the electrodes were ultra-sonicated for $5 \mathrm{~min}$ in 
ethanol and water, respectively. The aqueous polymerization solution $(0.01 \mathrm{M} \mathrm{EDOT}+0.1 \mathrm{M} \mathrm{NaPSS})$ was purged with $\mathrm{N}_{2}$ gas for $15 \mathrm{~min}$, and $\mathrm{N}_{2}$ flow was kept above the solution during the polymerization procedure. The conducting polymer PEDOT doped with $\mathrm{PSS}^{-}$, i.e. PEDOT(PSS), was electrodeposited on the working electrode by galvanostatic electrochemical polymerization using an Autolab General Purpose Electrochemical System (AUT30.FRA2-Autolab, Eco Chemie, B.V., The Netherlands) connected to a conventional one-compartment three-electrode electrochemical cell. The GC electrode was connected as the working electrode, a GC rod as auxiliary (counter) electrode, and a Metrohm double junction $\mathrm{Ag} / \mathrm{AgCl} / 3 \mathrm{M} \mathrm{KCl} / 0.1 \mathrm{M}$ NaPSS was used as the reference electrode. To produce polymerization charge (loading) of 1,5 , and $10 \mathrm{mC}$, a constant current of $0.014 \mathrm{~mA}$ $\left(0.2 \mathrm{~mA} / \mathrm{cm}^{2}\right)$ was applied for 71,355 , and $710 \mathrm{~s}$, respectively [8].

After polymerization, all the GC/PEDOT(PSS) electrodes were dried overnight in air before covering them with the ISM. Solid contact ion-selective electrodes (SCISEs) with thin-layer of ISM were prepared by spin-coating the corresponding $\mathrm{Pb}^{2+}$-selective or $\mathrm{Ca}^{2+}$-selective membrane cocktail onto the GC/PEDOT(PSS) electrodes placed vertically in a holder on a rotator. The rotation speed was $1500 \mathrm{rpm}$, and three drops of the membrane cocktail were added dropwise onto the rotating electrode surface. The volume of each drop was ca. $15 \mu \mathrm{l}$. A thin layer of ISM was formed, while the excess of the cocktail escaped the electrode surface due to the centrifugal force. The SCISEs with conventional thicklayer ISM were prepared by dropcasting $50 \mu \mathrm{l}$ aliquot of the corresponding membrane cocktail to cover the whole GC disk surface and the surrounding flat end of the PVC body. The same $\mathrm{Pb}^{2+}$-selective and $\mathrm{Ca}^{2+}$-selective membrane cocktails were used both for spin-coating and dropcasting techniques. The composition of the $\mathrm{Pb}^{2+}$-selective membrane cocktail in $\%(w / w)$ was $1 \%$ lead ionophore IV, 0.5\% KTpCIPB, $65.2 \%$ o-NPOE, and $33.3 \%$ PVC. These components were dissolved in THF (dry fraction of the membrane cocktail = $15 \%)$. The composition of $\mathrm{Ca}^{2+}$-selective membrane cocktail in $\%(w / w)$ was $0.8 \%$ calcium ionophore IV, $0.45 \%$ KTFPB, $65.85 \%$ o-NPOE, and $32.9 \%$ PVC dissolved in THF (dry fraction of the membrane cocktail $=15 \%$ ). The membranes were dried overnight followed by an overnight conditioning in $1 \mathrm{mM} \mathrm{Pb}\left(\mathrm{NO}_{3}\right)_{2}$ or $0.01 \mathrm{M} \mathrm{CaCl}_{2}$ before the measurements. The electrodes were stored in the same solutions between the measurements. For comparison, a $\mathrm{K}^{+}$-SCISE with $1 \mathrm{mC}$ PEDOT(PSS) loading covered with dropcast $\mathrm{K}^{+}$-selective ISM was also used $[24,25]$. The composition of the $\mathrm{K}^{+}$-selective membrane cocktail in $\%(w / w)$ was $1 \%$ valinomycin, $0.5 \%$ KTFPB, $1 \%$ ETH-500, 65.3\% DOS, and 32.2\% PVC. These components were dissolved in THF (dry fraction of the membrane cocktail $=15 \%$ ).

\section{Potentiometric and chronoamperometric measurements}

Potentiometric calibrations were performed to verify the proper functioning of the $\mathrm{Pb}^{2+}$ - and the $\mathrm{Ca}^{2+}$-selective SCISEs. Both potentiometric and coulometric calibrations were done following the protocol from our previous work [26]. In these measurements, $\mathrm{Pb}^{2+}$ - and $\mathrm{Ca}^{2+}$-SCISEs with variable loading of the PEDOT(PSS) (polymerization charge 1, 5, and $10 \mathrm{mC}$ ) covered either with spin-coated thin-layer ISM or dropcast thick-layer ISM were studied. Three replicates of $\mathrm{Pb}^{2+}$ and $\mathrm{Ca}^{2+}$-SCISEs were prepared for all the experiments.

The starting solution used in the calibration of $\mathrm{Pb}^{2+}$ SCISEs was $100 \mathrm{ml} 1 \mathrm{mM} \mathrm{Pb}\left(\mathrm{NO}_{3}\right)_{2}$ that was diluted with deionized water, whereas for $\mathrm{Ca}^{2+}$-SCISEs, the calibration started in $100 \mathrm{ml} 0.01 \mathrm{M} \mathrm{CaCl}_{2}+0.1 \mathrm{M} \mathrm{NaCl}$ (as constant ionic background) that was diluted using $0.1 \mathrm{M} \mathrm{NaCl}$. Removing $34.2 \mathrm{ml}$ of the electrolyte and replacing it with equal amount of deionized water or $0.1 \mathrm{M} \mathrm{NaCl}$ result in $\Delta \log a_{\mathrm{Pb} 2+}$ or $\Delta \log a_{\mathrm{Ca} 2+}=0.18$ decades/dilution step. A Metrohm double-junction $\mathrm{Ag} / \mathrm{AgCl} / 3 \mathrm{M} \mathrm{KCl} / 1 \mathrm{M} \mathrm{LiAc}$ was used as the reference electrode in all potentiometric, chronoamperometric, and coulometric measurements.

\section{Electrochemical impedance spectroscopy}

Electrochemical impedance spectroscopy (EIS) measurements were performed at the open circuit potential (OCP) of $\mathrm{Pb}^{2+}$-SCISEs and $\mathrm{Ca}^{2+}{ }_{-}$SCISEs in $0.1 \mathrm{M} \mathrm{Pb}\left(\mathrm{NO}_{3}\right)_{2}$ and $0.1 \mathrm{M}$ $\mathrm{CaCl}_{2}$, respectively. The Autolab Frequency Response Analyzer System (AUT20.FRA2-Autolab, Eco Chemie, B.V.) connected to a conventional one-compartment threeelectrode electrochemical cell was used to carry out the measurements. A Metrohm single-junction $\mathrm{Ag} / \mathrm{AgCl} / 3 \mathrm{M} \mathrm{KCl}$ was used as reference electrode and a glassy carbon rod as the counter electrode. The sinusoidal excitation signal with an excitation amplitude of $10 \mathrm{mV}$ (RMS) around the OCP was used in the frequency range $100 \mathrm{kHz}-10 \mathrm{mHz}$.

\section{Results and discussion}

Results from the potentiometric measurements revealed that the slopes of the linear part in the calibration curves for both $\mathrm{Pb}^{2+}{ }_{-}$-SCISEs and $\mathrm{Ca}^{2+}$-SCISEs were ca. $26 \pm 1 \mathrm{mV} /$ decade. These values were considered to be sufficiently close to the Nernstian value $(29.6 \mathrm{mV} /$ decade $)$ to be used further for chronoamperometric and coulometric measurements in this work.

In analogy with the case of monovalent cation-selective electrodes described earlier [23-26], the oxidation/reduction of the PEDOT(PSS) solid contact in the case of divalent 
cation-selective electrodes is expected to follow Eq. 1, taking the $\mathrm{Pb}^{2+}$-SCISE as an example.

$$
\begin{aligned}
& 2 \operatorname{PEDOT}^{+}\left(\mathrm{PSS}^{-}\right)_{\text {film }}+\mathrm{Pb}_{\mathrm{ISM}}^{2+} \\
& \quad+2 \mathrm{e}^{-} \leftrightarrow\left[\left(\operatorname{PEDOT}^{0}\left(\mathrm{PSS}^{-}\right)\right)_{2} \mathrm{~Pb}^{2+}\right]_{\text {film }}
\end{aligned}
$$

In the coulometric method, the potential between the working electrode (SCISE) and the reference electrode is kept constant during the chronoamperometric measurement by using a potentiostat. A decrease in the activity of the primary ion $\mathrm{Pb}^{2+}$, due to the dilution of the sample solution, will cause a decrease in the potential of the ISM-solution interface and thus a shift of the potential of the SCISE in the negative direction vs the reference electrode. As a result, the PEDOT(PSS) solid contact will be oxidized in order to compensate this drop in potential. The oxidation current flowing between the SCISE and the counter electrode is measured and integrated to obtain the cumulated charge $(Q)$ that is expected to be linearly proportional to the change in the logarithm of $\mathrm{Pb}^{2+}$ activity.
The chronoamperometric and coulometric response of the $\mathrm{Pb}^{2+}{ }_{-S C I S E s}$ and $\mathrm{Ca}^{2+}$-SCISEs, with PEDOT(PSS) as solid contact prepared using 1,5 , and $10 \mathrm{mC}$ polymerization charge and covered with $50 \mu \mathrm{l}$ dropcast ISM, is shown in Fig. 1. It is seen from Fig. $1 \mathrm{a}$ and e that a higher PEDOT(PSS) loading (higher redox capacitance) in the SCISEs leads to longer response times and also larger cumulated charge values. A thicker solid contact film means that a larger amount of PEDOT(PSS) is involved in the oxidation/reduction process and produces a higher charge, at a given activity change of the primary ion in the solution (Fig. $1 \mathrm{~b}$ and f). These results are in good qualitative agreement with the results from our previous work using $\mathrm{K}^{+}$-SCISEs [24].

As shown in Fig. 1, the current in the chronoamperograms of the $\mathrm{Pb}^{2+}$-SCISEs and $\mathrm{Ca}^{2+}$-SCISEs returned to the baseline within $5 \mathrm{~min}$ for the SCISEs having a $1 \mathrm{mC}$ PEDOT(PSS) solid contact. However, for the SCISEs having 5 and $10 \mathrm{mC}$ PEDOT(PSS) solid contacts, a longer equilibration time would be needed to reach equilibrium after successive dilutions. The cumulated charge vs time for $\mathrm{Pb}^{2+}$-SCISEs is

$\mathrm{Pb}^{2+}$-SCISE

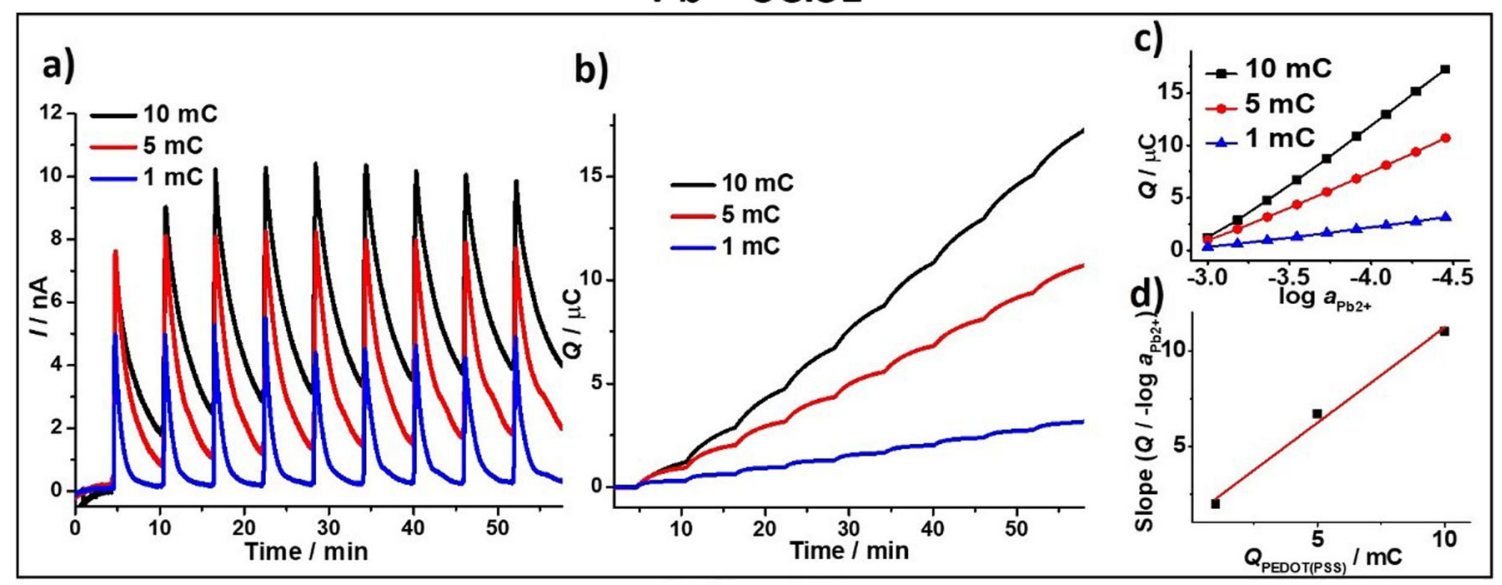

$\mathrm{Ca}^{2+}-\mathrm{SCISE}$

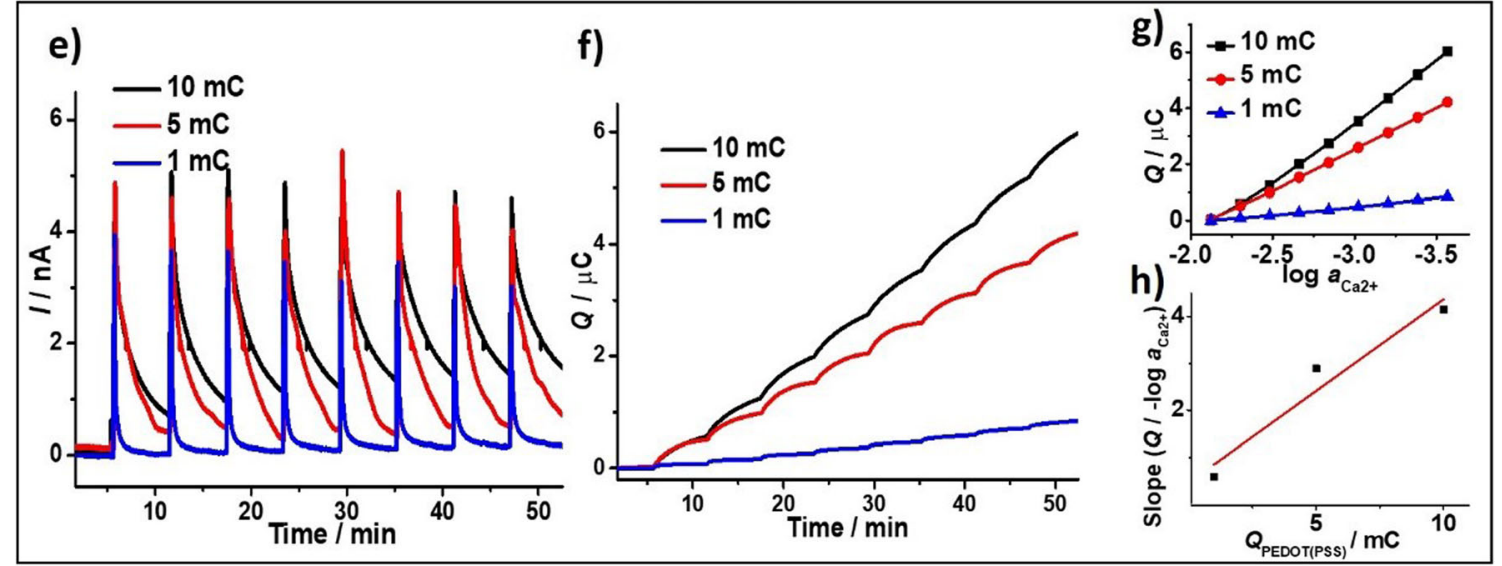

Fig. 1 Chronoamperograms (a, e), cumulated charge $Q$ vs time (b, f), $Q$ vs $\log a_{\mathrm{Pb} 2+}$ or $\log a_{\mathrm{Ca} 2+}(\mathbf{c}, \mathbf{g})$, and the slope ( $Q$ vs $\log a_{\mathrm{Pb} 2+}$ or $\left.\log a_{\mathrm{Ca} 2+}\right)$ vs the polymerization charge of PEDOT(PSS) solid contact $(\mathbf{d}, \mathbf{h})$ of
$\mathrm{Pb}^{2+}$-SCISEs and $\mathrm{Ca}^{2+}$-SCISEs with 1,5 , and $10 \mathrm{mC}$ PEDOT(PSS) as solid contact covered with $50 \mu$ l dropcast thick ISM 
presented in Fig. 1b, and the cumulated charge $Q$ vs $\log a_{\mathrm{Pb} 2+}$ is shown in Fig. 1c. As can be seen, the cumulated charge $Q$ is linearly proportional to $\log a_{\mathrm{Pb} 2+}$ and the obtained $Q$ value is amplified by increasing the thickness (redox capacitance) of the solid contact. However, the slope ( $Q$ vs $\left.\log a_{\mathrm{Pb} 2+}\right)$ does not increase linearly with the polymerization charge of PEDOT(PSS) as shown in Fig. 1d, which can be explained by the fact that the current response does not return back to zero after successive dilutions for the 5 and $10 \mathrm{mC}$ PEDOT(PSS) solid contacts (Fig. 1a). The $\mathrm{Ca}^{2+}$-SCISEs (Fig. 1g) show the same trend as the $\mathrm{Pb}^{2+}$-SCISEs, i.e., the cumulated charge $Q$ is linearly proportional to $\log a_{\mathrm{Ca} 2+}$. Similarly, for $\mathrm{Ca}^{2+}$-SCISEs, the slope ( $Q$ vs $\left.\log a_{\mathrm{Ca} 2+}\right)$ does not increase linearly with the PEDOT(PSS) loading as shown in the inset of Fig. 1h. Clearly, for these SCISEs with a dropcast thick ISM, the amplification effect can be only partly utilized when limiting the response time to $5 \mathrm{~min}$, which was chosen for practical reasons.

The reproducibility of the coulometric response for $\mathrm{Pb}^{2+}$ SCISEs with $1 \mathrm{mC}$ PEDOT(PSS) solid contact covered with dropcast ISM is shown in Fig. 2. As shown in Fig. 2 a and b, the chronoamperometric signals and the cumulated charge $Q$ are almost identical for the measurements that were carried out with two identical $\mathrm{Pb}^{2+}{ }_{-}$SCISEs $\left(\mathrm{Pb}^{2+}{ }_{-}\right.$SCISE No. 1 and $\mathrm{Pb}^{2+}$ SCISE No.2 in Fig. 2) using the same dilution protocol $(\Delta \log$ $a_{\mathrm{Pb} 2+}=0.18$ decades/dilution step). A slightly higher cumulated charge vs time response for a repeated measurement (Fig. 2b) can be due to slight increase in the sensitivity (potentiometric slope) of the electrode after the first measurement to low concentrations.

A comparison of the chronoamperograms of a $\mathrm{K}^{+}$-SCISE and a $\mathrm{Pb}^{2+}$-SCISE recorded under five successive dilution steps with $\Delta \log a_{\mathrm{K}+}$ and $\Delta \log a_{\mathrm{Pb} 2+}=0.18$ decades/dilution step is shown in Fig. 3. For both electrodes, the solid contact PEDOT(PSS) was prepared with $1 \mathrm{mC}$ polymerization charge and covered with the relevant dropcast thick ISMs. Theoretically, according to the Nernst equation, the potential change of the monovalent $\mathrm{K}^{+}$-SCISE should be twice that of the divalent $\mathrm{Pb}^{2+}$-SCISE for a given dilution step, here $\Delta \log$ $a_{\mathrm{K}+}$ and $\Delta \log a_{\mathrm{Pb} 2+}=0.18$ decades/dilution step. Hence, also the cumulated charge $Q$ vs time is expected to be twice as large for the $\mathrm{K}^{+}$-SCISE compared with that for the $\mathrm{Pb}^{2+}$ SCISE. As can be seen in Fig. 3b, the difference in $Q$ is smaller than expected. This apparent deviation from the theoretical prediction can be due to differences in the redox capacitance of PEDOT(PSS) in the presence of $\mathrm{Pb}^{2+}$ compared with $\mathrm{K}^{+}$or ion-transport limitations within the SCISEs. As seen in Fig. 3a, the $\mathrm{Pb}^{2+}{ }_{-}$SCISE shows a faster response than the $\mathrm{K}^{+}$SCISE for a given concentration change. Thus, after the same measurement time $(5 \mathrm{~min})$, the charge accumulated by the $\mathrm{Pb}^{2+}$-SCISE is closer to the equilibrium value than that accumulated by the $\mathrm{K}^{+}$-SCISE, which will influence the cumulated charge presented in Fig. $3 b$.

When comparing the $Q$ vs $\log a$ curves for the $\mathrm{Pb}^{2+}$-SCISE and the $\mathrm{Ca}^{2+}{ }_{-}$SCISE (Fig. 1), it is evident that the $\mathrm{Pb}^{2+}$-SCISE gives a considerably higher charge than the $\mathrm{Ca}^{2+}$-SCISE for the same polymerization charge of the PEDOT(PSS) layer. This indicates that the effective redox capacitance of PEDOT(PSS) is significantly higher in the presence of $\mathrm{Pb}^{2+}$ than in the presence of $\mathrm{Ca}^{2+}$ ions.

Figure 4 shows the effect of the ISM thickness on the chronoamperometric and coulometric response for $\mathrm{Pb}^{2+}$ SCISEs and $\mathrm{Ca}^{2+}$-SCISEs with 1,5 , and $10 \mathrm{mC}$ loading of PEDOT(PSS) solid contact covered either with dropcast thick or spin-coated thin ISM. The dilution was again done with $0.18 \Delta \log a_{\mathrm{Pb} 2+}$ or $\Delta \log a_{\mathrm{Ca} 2+}$ steps. For the $\mathrm{Pb}^{2+}$-SCISEs, the chronoamperograms (solid line) and the corresponding cumulated charge vs time (dashed line) during two dilution steps are shown in Fig. $4 \mathrm{a}-\mathrm{c}$. The corresponding results for the $\mathrm{Ca}^{2+}$-SCISEs are shown in Fig. $4 \mathrm{~d}-\mathrm{f}$.

The chronoamperometric and coulometric results in Fig. 4 show that a thin ISM (lower bulk resistance) gives a faster coulometric response than a thick ISM (higher bulk resistance) for both the $\mathrm{Pb}^{2+}$-SCISEs and the $\mathrm{Ca}^{2+}{ }_{-}$SCISEs. The results in Fig. 4 also show that the coulometric signal is amplified with increasing thickness (increasing redox
Fig. 2 Chronoamperograms (a) and cumulated charge $Q$ vs time (b) recorded for $\mathrm{Pb}^{2+}$-SCISEs with $1 \mathrm{mC}$ PEDOT(PSS) covered with dropcast thick ISM. The starting solution is $1 \mathrm{mM}$ $\mathrm{Pb}\left(\mathrm{NO}_{3}\right)_{2}$ diluted with deionized water with $\Delta \log a_{\mathrm{Pb} 2+}=0.18$ decades/dilution step
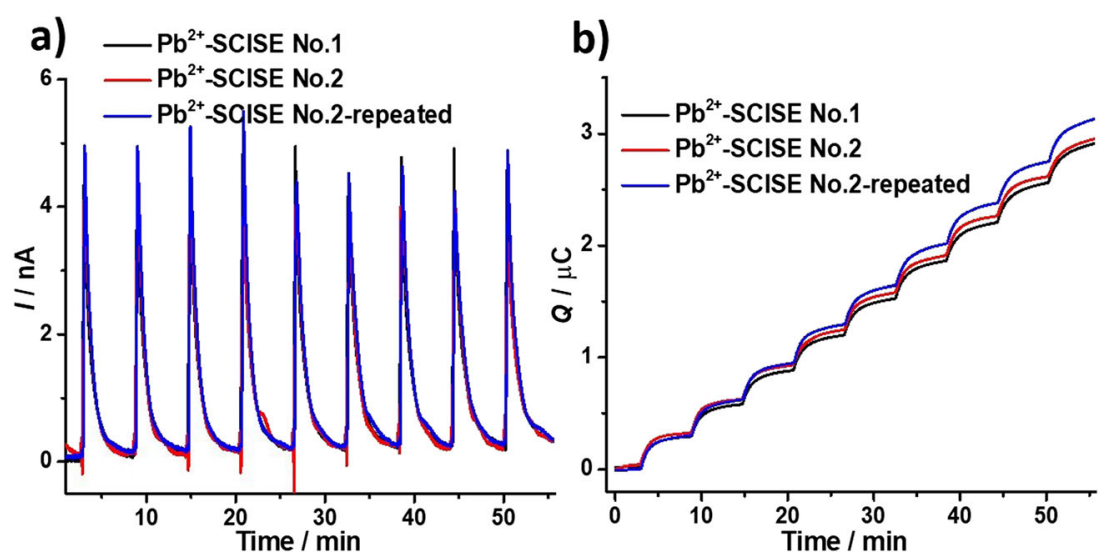
Fig. 3 Chronoamperograms (a) and cumulated charge $Q$ vs time (b) for a $\mathrm{K}^{+}$-SCISE and $\mathrm{a} \mathrm{Pb}^{2+}$ SCISE with $1 \mathrm{mC}$ PEDOT(PSS) solid contact covered with dropcast thick ISM. The starting solution for the $\mathrm{Pb}^{2+}$-SCISE is $1 \mathrm{mM} \mathrm{Pb}\left(\mathrm{NO}_{3}\right)_{2}$ diluted with deionized water, and for the $\mathrm{K}^{+}$SCISE, it is $0.01 \mathrm{M} \mathrm{KCl}+0.1 \mathrm{M}$ $\mathrm{NaCl}$ that was diluted with $0.1 \mathrm{M}$ $\mathrm{NaCl}$
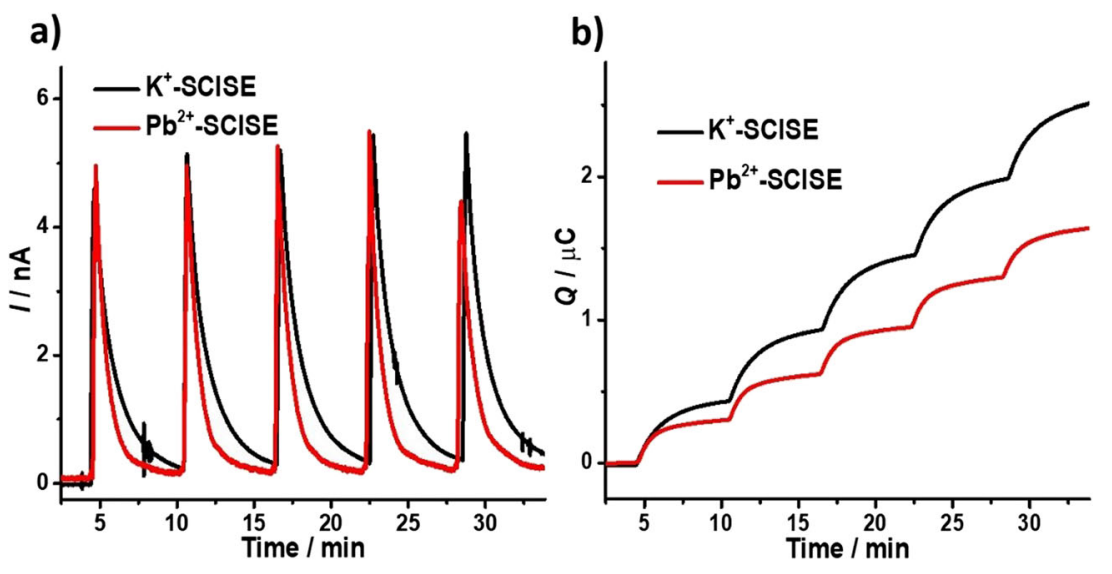

capacitance) of the PEDOT solid contact. These results are in qualitative agreement with results obtained for monovalent cations [24-26].

However, the results shown in Fig. 4 illustrate some unique features of the amperometric and coulometric signal when applied to SCISEs for the detection of divalent cations. A detailed comparison of the $\mathrm{Pb}^{2+}$-SCISEs and $\mathrm{Ca}^{2+}$-SCISEs with $1 \mathrm{mC}$ PEDOT(PSS) as solid contact shows three interesting new attributes. Firstly, the chronoamperometric and coulometric responses for the $\mathrm{Pb}^{2+}$-SCISEs are almost independent of the ISM thickness (Fig. 4a), which is not the case for the $\mathrm{Ca}^{2+}$-SCISEs (Fig. 4d). Secondly, the cumulated charge for the $\mathrm{Pb}^{2+}$-SCISEs (Fig. 4a) is about twice as high compared with the $\mathrm{Ca}^{2+}$-SCISEs (Fig. 4d). Thirdly, the coulometric response is slower for the $\mathrm{Pb}^{2+}$-SCISEs (Fig. 4a) than for the $\mathrm{Ca}^{2+}$-SCISEs (Fig. 4d) in the case of spin-coated thin ISMs. These results together indicate that the coulometric response of the $\mathrm{Pb}^{2+}$-SCISE is mainly limited by the PEDOT(PSS) layer, while the coulometric response of the $\mathrm{Ca}^{2+}$-SCISE is mainly limited by the ISM layer. With increasing thickness of the PEDOT(PSS) layer, the differences in the cumulated charge for the $\mathrm{Pb}^{2+}$-SCISEs and $\mathrm{Ca}^{2+}$-SCISEs become smaller, which shows that the redox capacitance of PEDOT(PSS) can be utilized to a smaller extent in the

\section{$\mathrm{Pb}^{2+}-\mathrm{SCISE}$}

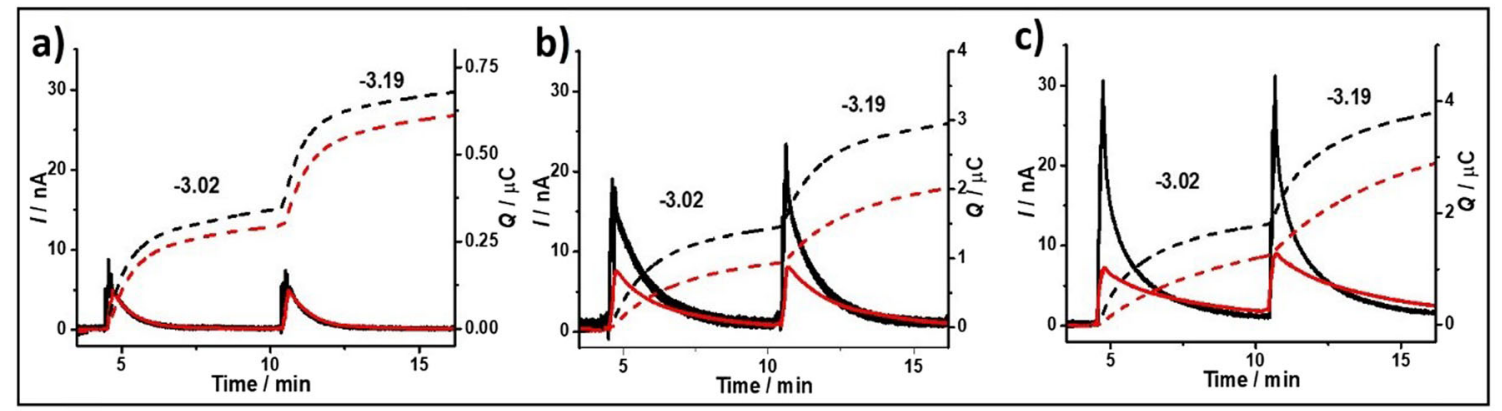

$\mathrm{Ca}^{2+}-\mathrm{SCISE}$
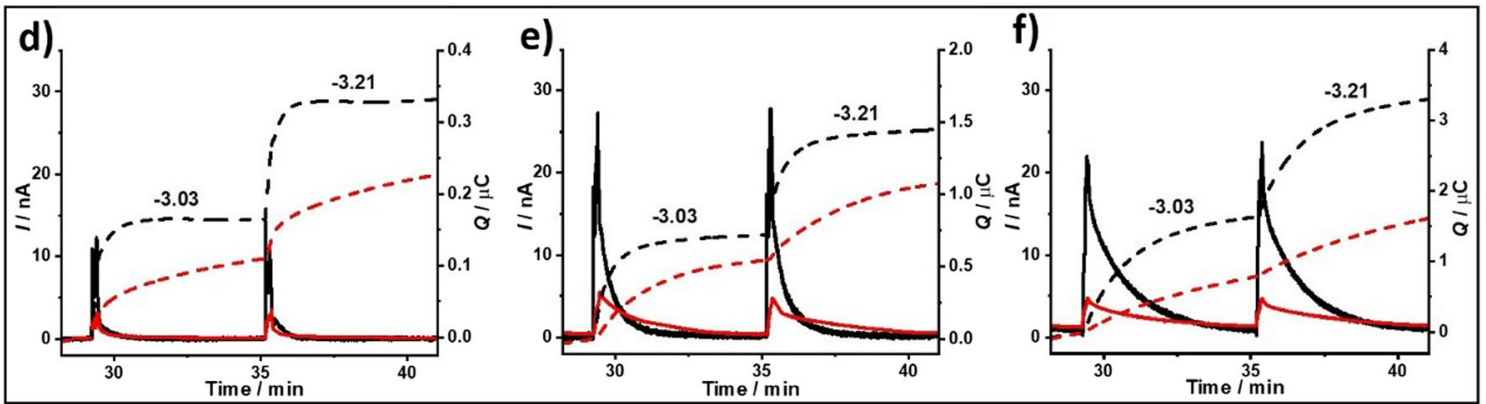

Fig. 4 Enlargement of the chronoamperograms (solid line) for $\mathrm{Pb}^{2+}$ SCISEs and $\mathrm{Ca}^{2+}$-SCISEs and the corresponding cumulated charge vs time (dashed line) with $1 \mathrm{mC}(\mathbf{a}, \mathbf{d}), 5 \mathrm{mC}(\mathbf{b}, \mathbf{e})$, and $10 \mathrm{mC}(\mathbf{c}, \mathbf{f})$ PEDOT(PSS) solid contact covered with spin-coated thin-layer (black) or dropcast (red) ISM, respectively. The primary ion activity $(\log a)$ after each dilution step is shown in the figure. The results for the $\mathrm{Pb}^{2+}$-SCISEs recorded in $\mathrm{Pb}\left(\mathrm{NO}_{3}\right)_{2}$ solutions (without background electrolyte) and for the $\mathrm{Ca}^{2+}$-SCISEs in $\mathrm{CaCl}_{2}$ solutions (with $0.1 \mathrm{M} \mathrm{NaCl}$ as constant ionic background) 
Fig. 5 Electrochemical impedance spectra recorded for $\mathrm{Pb}^{2+}$-SCISEs and $\mathrm{Ca}^{2+}$-SCISEs with 1 and $10 \mathrm{mC}$ PEDOT(PSS) as solid contact, covered either with dropcast thick-layer ISM (a) or spin-coated thin-layer ISM (b). The measurements were done in $0.1 \mathrm{M} \mathrm{Pb}\left(\mathrm{NO}_{3}\right)_{2}$ and $0.1 \mathrm{M} \mathrm{CaCl}_{2}$ for $\mathrm{Pb}^{2+}$ - and $\mathrm{Ca}^{2+}$-SCISEs, respectively. Dc-potential = open circuit potential, and frequency range $=100 \mathrm{kHz}-10 \mathrm{mHz}$
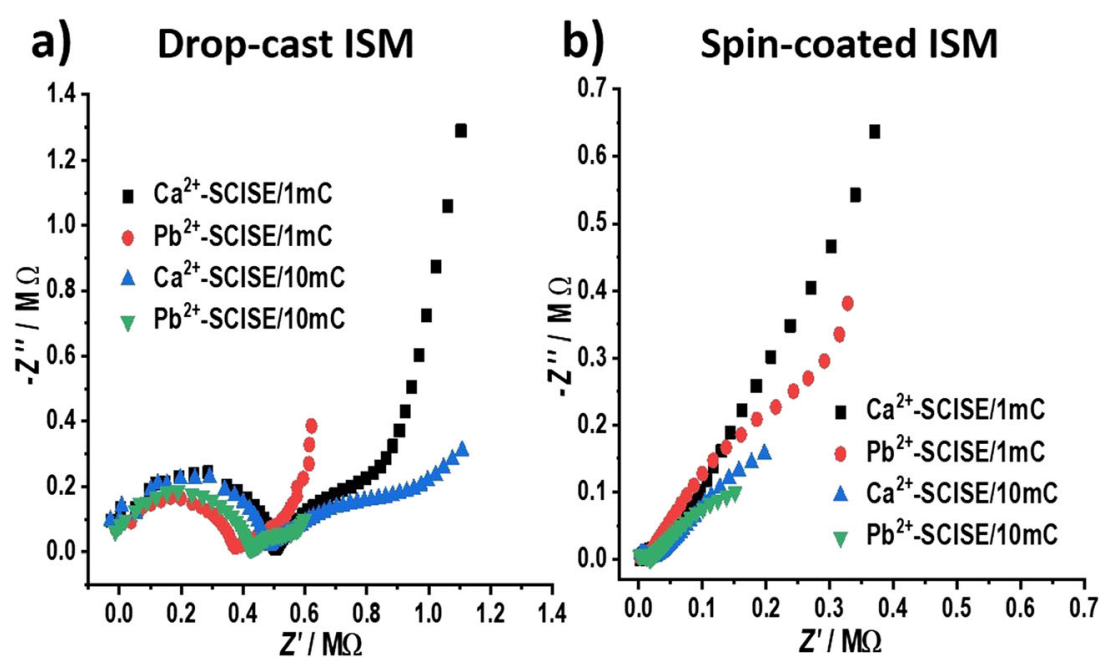

presence of $\mathrm{Pb}^{2+}$ (compared with $\mathrm{Ca}^{2+}$ ) when the PEDOT(PSS) layer becomes thicker. An increase in the PEDOT(PSS) thickness (and redox capacitance) means that a larger number of ions need to be transported through the PEDOT(PSS) as well as through the ISM for a given change of ion activity in solution. This may then cause larger concentration polarization in either the PEDOT(PSS) layer or in the ISM layer (or both).

Electrochemical impedance spectra for $\mathrm{Pb}^{2+}$-SCISEs (in $0.1 \mathrm{M} \mathrm{Pb}\left(\mathrm{NO}_{3}\right)_{2}$ ) and $\mathrm{Ca}^{2+}$-SCISEs (in $0.1 \mathrm{M} \mathrm{CaCl}_{2}$ ) with 1 and $10 \mathrm{mC}$ PEDOT(PSS) as solid contact and dropcast (thick) ISMs are shown in Fig. 5a. The corresponding results for spincoated (thin) ISMs are shown in Fig. 5b. The SCISEs with dropcast ISM show a high-frequency semicircle corresponding to the bulk resistance $(450 \pm 60 \mathrm{k} \Omega)$ and geometric capacitance $(27 \pm 2 \mathrm{pF})$ of the ISM (Fig. 5a). This semicircle is hardly visible for SCISEs with spin-coated ISMs due to the low bulk resistance (Fig. 5b). The low-frequency part of the impedance spectra shows that the overall resistance of the $\mathrm{Ca}^{2+}$-SCISEs is about twice that of the $\mathrm{Pb}^{2+}$-SCISEs in the case of dropcast ISMs (Fig. 5a).

The imaginary impedance $\left(-Z^{\prime \prime}\right)$ values of the lowest frequency point $(10 \mathrm{mHz})$ was used to estimate the low- frequency (redox) capacitance $\left(C_{\mathrm{L}}\right)$ of the PEDOT(PSS) layer in the SCISEs. The estimated $C_{\mathrm{L}}$ values for the $\mathrm{Pb}^{2+}$-SCISEs and $\mathrm{Ca}^{2+}$-SCISEs are shown in Table 1 . The results in Table 1 show that the low-frequency capacitance $\left(C_{\mathrm{L}}\right)$ for the SCISEs increases with increasing polymerization charge of PEDOT(PSS). Interestingly, $C_{\mathrm{L}}$ is independent of the ISM thickness for the $\mathrm{Pb}^{2+}$-SCISE. This shows that the oxidation/ reduction of PEDOT(PSS) is not limited by ion transport in the ISM but rather due to charge transport limitations in the PEDOT(PSS) layer of the $\mathrm{Pb}^{2+}$-SCISE. On the contrary, for the $\mathrm{Ca}^{2+}$-SCISE, the value of $C_{\mathrm{L}}$ decreases with increasing thickness of the ISM, indicating that in this case, the oxidation/reduction of PEDOT(PSS) is limited by ion transport in the ISM for the $\mathrm{Ca}^{2+}$-SCISE.

These impedance results (Fig. 5; Table 1) are in agreement with the coulometric results for $\mathrm{Ca}^{2+}$-SCISEs and $\mathrm{Pb}^{2+}$ SCISEs in Fig. 4. When comparing the influence of the polymerization charge of PEDOT(PSS) for a given ISM thickness, one can see that $C_{\mathrm{L}}$ increases by ca. 4 times when the polymerization charge increases from 1 to $10 \mathrm{mC}$ in the case of $\mathrm{Pb}^{2+}$-SCISEs and $\mathrm{Ca}^{2+}$-SCISEs.

The observation that the coulometric response for the $\mathrm{Pb}^{2+}$ SCISE was limited by ion transport in the PEDOT(PSS) layer
Table 1 Low-frequency capacitance $\left(C_{\mathrm{L}}\right)$ values for $\mathrm{Pb}^{2+}$ SCISEs and $\mathrm{Ca}^{2+}$-SCISEs estimated from the impedance spectra in Fig. 5

\begin{tabular}{lclr}
\hline Electrode & $\begin{array}{l}\text { Polymerization charge } \\
\text { of PEDOT(PSS) }(\mathrm{mC})\end{array}$ & ISM & $C_{\mathrm{L}}(\mu \mathrm{F})$ \\
\hline $\mathrm{Pb}^{2+}$-SCISE & 1 & Spin-coated & 42 \\
$\mathrm{~Pb}^{2+}$-SCISE & 1 & Dropcast & 41 \\
$\mathrm{~Pb}^{2+}$-SCISE & 10 & Spin-coated & 160 \\
$\mathrm{~Pb}^{2+}$-SCISE & 10 & Dropcast & 160 \\
$\mathrm{Ca}^{2+}$-SCISE & 1 & Spin-coated & 25 \\
$\mathrm{Ca}^{2+}$-SCISE & 1 & Dropcast & 12 \\
$\mathrm{Ca}^{2+}$-SCISE & 10 & Spin-coated & 101 \\
$\mathrm{Ca}^{2+}$-SCISE & 10 & Dropcast & 51 \\
\hline
\end{tabular}


is intriguing. One possibility is that interactions between $\mathrm{Pb}^{2+}$ and PEDOT(PSS) retard the transport of $\mathrm{Pb}^{2+}$ in and out of PEDOT(PSS). The affinity between various cations and $\mathrm{PSS}^{-}$ was reported to decrease in the following order [29]: $\mathrm{Ba}^{2+}>$ $\mathrm{Pb}^{2+}>\mathrm{Sr}^{2+}>\mathrm{Ca}^{2+}>\mathrm{Cu}^{2+}>\mathrm{Co}^{2+}>\mathrm{Ni}^{2+}>\mathrm{Mg}^{2+}>\mathrm{H}^{+}>\mathrm{K}^{+}>$ $\mathrm{Na}^{+}>\mathrm{Li}^{+}$. Based on these results, $\mathrm{Pb}^{2+}$ interacts more strongly with $\mathrm{PSS}^{-}$than $\mathrm{Ca}^{2+}$ and $\mathrm{K}^{+}$. Therefore, the transport of $\mathrm{Pb}^{2+}$ in PEDOT(PSS) may be limited due to complexation between $\mathrm{Pb}^{2+}$ and $\mathrm{PSS}^{-}$. Another possible explanation is that $\mathrm{Pb}^{2+}$ being a "soft" cation interacts with sulfur atoms in PEDOT. This is supported by earlier results showing significant interactions between the "soft" $\mathrm{Ag}^{+}$cation and poly(3octylthiophene) [30].

\section{Conclusions}

In this work, the transfer of divalent cations $\left(\mathrm{Pb}^{2+}, \mathrm{Ca}^{2+}\right)$ in solid contact ISEs (SCISEs) was studied by chronoamperometry, constant potential coulometry, and electrochemical impedance spectroscopy. The electrochemical characteristics of lead-selective SCISEs $\left(\mathrm{Pb}^{2+}\right.$-SCISEs) and calcium-selective SCISEs $\left(\mathrm{Ca}^{2+}\right.$-SCISEs) were investigated by varying the thickness of the PEDOT(PSS) solid contact layer and the thickness of the ion-selective membrane. Results from coulometric measurements show that the cumulated charge is linearly proportional to the logarithm of the activity of the primary ion in the solution within the range where the potentiometric response of the SCISE is linear. The signal can be amplified by increasing the thickness of PEDOT(PSS) in a similar way as in SCISEs for the detection of monovalent cations studied earlier. The results show further that the coulometric response of the $\mathrm{Pb}^{2+}$-SCISE is limited by charge (ion) transport in PEDOT(PSS), while the response of the $\mathrm{Ca}^{2+}$-SCISEs is limited mainly by ion transport in the ionselective membrane. The limited transport of $\mathrm{Pb}^{2+}$ in PEDOT(PSS) was tentatively explained by interactions between $\mathrm{Pb}^{2+}$ and PEDOT(PSS). Thus, a decrease in the thickness of the ion-selective membrane will only marginally shorten the response time for coulometric $\mathrm{Pb}^{2+}$-SCISEs when PEDOT(PSS) is used as solid contact.

Acknowledgments This work is part of the activities of the Johan Gadolin Process Chemistry Centre (PCC) at Åbo Akademi University.

Authors' contributions Tingting Han: formal analysis and investigation; writing - original draft preparation.

Zekra Mousavi: formal analysis and investigation; writing - review and editing.

Ulriika Mattinen: methodology; formal analysis and investigation; writing - review and editing.

Johan Bobacka: conceptualization; methodology; writing - review and editing; funding acquisition; supervision.
Funding information Open access funding provided by Abo Akademi University (ABO). This work was funded by the Academy of Finland (project no. 317829).

Availability of data and material Data available upon request.

\section{Compliance with ethical standards}

Conflict of interest The authors declare that they have no conflict of interest.

Code availability Not applicable.

Open Access This article is licensed under a Creative Commons Attribution 4.0 International License, which permits use, sharing, adaptation, distribution and reproduction in any medium or format, as long as you give appropriate credit to the original author(s) and the source, provide a link to the Creative Commons licence, and indicate if changes were made. The images or other third party material in this article are included in the article's Creative Commons licence, unless indicated otherwise in a credit line to the material. If material is not included in the article's Creative Commons licence and your intended use is not permitted by statutory regulation or exceeds the permitted use, you will need to obtain permission directly from the copyright holder. To view a copy of this licence, visit http://creativecommons.org/licenses/by/4.0/.

\section{References}

1. Lewenstam A (2008) Routines and challenges in clinical application of electrochemical ion-sensors. Electroanalysis 26:1171-1181

2. Bakker E, Bühlmann P, Pretsch E (1997) Carrier-based ion-selective electrodes and bulk optodes. 1. General characteristics. Chem Rev 97(8):3083-3132

3. Bühlmann P, Pretsch E, Bakker E (1998) Carrier-based ion-selective electrodes and bulk optodes. 2. Ionophores for potentiometric and optical sensors. Chem Rev 29:1593-1688

4. Zuliani C, Diamond D (2012) Opportunities and challenges of using ion-selective electrodes in environmental monitoring and wearable sensors. Electrochim Acta 84:29-34

5. Bobacka J, Ivaska A, Lewenstam A (2008) Potentiometric ion sensors. Chem Rev 108(2):329-351

6. Sokalski T, Ceresa A, Zwickl T, Pretsch E (1997) Large improvement of the lower detection limit of ion-selective polymer membrane electrodes. J Am Chem Soc 119(46):11347-11348

7. Cadogan A, Gao Z, Lewenstam A, Ivaska A, Diamond D (1992) All-solid-state sodium-selective electrode based on a calixarene ionophore in a poly(vinyl chloride) membrane with a polypyrrole solid contact. Anal Chem 64(21):2496-2501

8. Bobacka J (1999) Potential stability of all-solid-state ion-selective electrodes using conducting polymers as ion-to-electron transducers. Anal Chem 71(1999):4932-4937

9. Kisiel A, Micahlska A, Maksymiuk K (2007) Plastic reference electrodes and plastic potentiometric cells with dispersion cast poly(3,4-ethylenedioxythiophene) and poly(vinyl chloride) based membranes. Bioelectrochem 71(1):75-80

10. Lisak G, Sokalski T, Bobacka J, Harju L, Lewenstam A (2010) A study on lowering the detection limit with solid-state lead-selective electrodes. Talanta 83(2):436-440

11. Lewenstam A, Bobacka J, Ivaska A (1994) Mechanism of ionic and redox sensitivity of p-type conducting polymers. Part I Theory. J Electroanal Chem 368(1-2):23-31 
12. Bobacka J, Gao Z, Ivaska A, Lewenstam A (1994) Mechanism of ionic and redox sensitivity of p-type conducting polymers. Part II Experimental study of polypyrrole. J Electroanal Chem 368:33-41

13. Vanamo U, Bobacka J (2014) Electrochemical control of the standard potential of solid-contact ion-selective electrodes having a conducting polymer as ion-to-electron transducer. Electrochim Acta 122:316-321

14. Vanamo U, Bobacka J (2014) Instrument-free control of the standard potential of potentiometric solid-contact ion-selective electrodes by short-circuiting with a conventional reference electrode. Anal Chem 86(21):10540-10545

15. Ding J, Yu N, Wang X, Qin W (2018) Sequential and selective detection of two molecules with a single solid-contact chronopotentiometric ion-selective electrode. Anal Chem 90(3): 1734-1739

16. Bakker E (2016) Electroanalysis with membrane electrodes and liquid-liquid interfaces. Anal Chem 88(1):395-413

17. Ding J, Qin W (2009) Current-driven ion fluxes of polymeric membrane ion-selective electrode for potentiometric biosensing. J Am Chem Soc 131(41):14640-14641

18. Bakker E (2014) Enhancing ion-selective polymeric membrane electrodes by instrumental control. Trends Anal Chem 53:98-105

19. Guo J, Amemiya S (2006) Voltammetric heparin-selective electrode based on thin liquid membrane with conducting polymermodified solid support. Anal Chem 78(19):6893-6902

20. Kim Y, Amemiya S (2008) Stripping analysis of nanomolar perchlorate in drinking water with a voltammetric ion-selective electrode based on thin-layer liquid membrane. Anal Chem 80(15): 6056-6065

21. Crespo GA, Cuartero M, Bakker E (2015) Thin layer ionophorebased membrane for multianalyte ion activity detection. Anal Chem 87(15):7729-7737
22. Cuartero M, Crespo GA, Bakker E (2016) Ionophore-based voltammetric ion activity sensing with thin layer membranes. Anal Chem 88(3):1654-1660

23. Hupa E, Vanamo U, Bobacka J (2015) Novel ion-to-electron transduction principle for solid-contact ISEs. Electroanalysis. 27(3): 591-594

24. Vanamo U, Hupa E, Yrjänä V, Bobacka J (2016) New signal readout principle for solid-contact ion-selective electrodes. Anal Chem 88(8):4369-4374

25. Han T, Vanamo U, Bobacka J (2016) Influence of electrode geometry on the response of solid-contact ion-selective electrodes when utilizing a new coulometric signal readout method. ChemElectroChem. 3(12):2071-2077

26. Han T, Mattinen U, Bobacka J (2019) Improving the sensitivity of solid-contact ion-selective electrodes by using coulometric signal transduction. ACS Sensors 4(4):900-906

27. Jarolímová Z, Han T, Mattinen U, Bobacka J, Bakker E (2018) Capacitive model for coulometric readout of ion-selective electrodes. Anal Chem 90(14):8700-8707

28. Kondratyeva YO, Tolsopjatova EG, Kirsanov DO, Mikhelson KM (2020) Chronoamperometric and coulometric analysis with ionophore-based ion-selective electrodes, a modified theory and the potassium ion assay in serum samples. Sens Act B 310:127894

29. Chen M, Shafer-Peltier K, Randtke SJ, Peltier E (2018) Competitive association of cations with poly(sodium 4styrenesulfonate) (PSS) and heavy metal removal from water by PSS-assisted ultrafiltration. Chem Eng J 344:155-164

30. Vázquez M, Bobacka J, Ivaska A (2005) Potentiometric sensors for $\mathrm{Ag}^{+}$based on poly(3-octylthiophene) (POT). J Solid State Electrochem 9(12):865-873

Publisher's note Springer Nature remains neutral with regard to jurisdictional claims in published maps and institutional affiliations. 